2.

\title{
Krebs-Infiltration der Lunge*).
}

Von Dr. C. Skrzeezka.

Frau R.; fl Jahre alt, leidet am Carcinoma mammae dextrae, welches zuexat vor 8 Jahren, während Patientin jhr letztes Kind säugte, aufgetreten war, dann gich während 5 Jahre angeblich nicht weiter entwickelte, vor $\mathbf{3}$ Jahren jedoch in wenigen Monaten schnell eine bedeutende Grösse erreichte. Der nun vorgenommenen Exstirpation der Knoten folgte bald ein Recidiv und die zum zweiten Male ausgeführte 0peration hatte keinen besseren Erfolg. Das Allgemeinbefinden und der Ernährungszustand der Kranken soll dabei ziemlich gut gewesen sein. Im Decomber 1855 stellte sich ein hartnäekiger Husten mit schaumigen weissen Sputis ein; bei körperlicher Anstrengung Athemnoth. Ostern 1856 wurde sie vom Armenarzte des Viertels an linksseitiger Pneumonie behandelt. Im Juli 1856 kam die Patientin in poliklinische Behandlung. Sie war ziemlich stark abgemagert, das Gesicht etwas cyanotisch und gedunsen, die Unterschenkel und Füsse oedematös. In der rechten Mamma und der rechten Achselgrube melre Scirrhusknoten, stark geschwellte Lymphdrüsen in der Fossa supraclavicularis dextra und den Hals entlang bis zum Processus mastoideus hinauf. Athemnoth und Husten mässig, doch werden beide augenblicklich vermehrt, wenn Patientin versucht, sich auf die linke Seite zu legen. Sputa weiss, schaumig. Kein Fieber, Verdauung bis auf mässige Obstruction gut. Die rechte Thoraxhälfte ist ausgedehnt, Intercostalräume erweitert und verstrichen, unbeweglich. Der Percussionston ist von oben bis unten, vorn wie binten dumpf und leer, Athmungsgeräusch nirgend börbar. Die linke Thoraxbälfte gibt normalen Percussionston und hat scharf-vesiculaires Athmen. Herztöne rein. Leber vergrössert und herabgedrängt, reicht 3 Zoll unter den Nabel. Ibre Oberfläche jst ungleich, höckrig, man fühlt deutlich mehrere sehr empfindliche Knollen.

Bei Gebrauch von Squilla und Eisen bessert sich der Zustand, der Athem wird freier, die Oedeme schwinden, so dass Patientin im Stande ist, ihren Geschäften nachzugehen, jedoch schon im 0ctober sucht sie wieder Hülfe. Die alten Beschwerden sind in erhöhtem Grade wieder eingetreten und steigern sich dauernd. Anfangs November erfolgte der Tod.

Section: In der rechten Pleurahöhle findet sich ein bedentender Erguss blutig-seröser Flüssigkeit, untermischt mit zahlreichen, roth gefärbten Fibringerinnseln. Die Lunge liegt völlig comprimirt hinten, oben an der Wirbelsäule an. Der

*) Das Präparat wurde mir von Herrn Prof. Moeller, die Krankengeschichte von Herrn Dr. Bohn freundlichst mitgetheilt. 
Pleuraüberzug derselben ist glatt, gelbröthlich gefärbt und circa $\frac{1}{2}$ I.in. dick, die Lappen der Lunge völlig miteinander verwachsen. Die Lunge selbst ist durchaus luftleer, von lederartig zäber Consistenz, die Schnittflächen völlig glatt. Die Färbung ist blaugrau, doch ist sie überall, besonders in der unteren Hälfte, dicht durchsprengt von weisslichgrauen, theils ziemlich scharf circumscripten, theils mehr diffusen Flecken, die sich übrigens, ilure Farbe ausgenommen, in nichts von den blaugrauen Partien zu unterscheiden scheinen.

Die linke Lunge adhärirt an mehreren Stellen; sie ist ibrer Form und dem Volum nach ziemlich normal. An der gegen das Mediastinum sehenden Fläche bemerkt man zahlreiche, von der Pleura überzogene, jedoch dicht unter ihr liegende und verschieden tief in die Lungensubstanz hineinragende, weissgraue, scharf umschriebene, derbe Knoten von Erbsen- bis Wallnussgrösse. Im Uebrigen ist die ganze Lunge stark oedematös. - In dieser Lunge haben wir offenbar die gewöhnliche, so häufig secundär in derselben vorkommende Form von Krebs vor uns; anders verhält es sich mit der rechten Lunge. Die mikroskopische Untersuchung zeigt in den blaugrauen Partien der Lunge völlig normales, nur comprimirtes Gewebe; in den weissgrauen Stellen ist das Lungengewebe selbst auch völlig normal, nur sind die Höhlıngen der Lungenbläschen völlig erfüllt mit feinen Fetttröpfchen (theils isolirten, theils zu Häufchen conglomerirten), ferner mit feinkörnigem Detritus und hauptsächlich mit Zellen verschiedener Form und Grösse, mit einfachem oder mehreren Kernen, zum Theil erfüllt mit Fettröpfchen. Von einem Krebsgeräste war keine Spur zu finden. - Wir haben hier also die dritte Rokitansk ysche, seltenste Form von Lungenkrebs vor uns, die sogenannte krebsige Pneumonie. Unser Fall bat nun noch das Eigenthümliche, dass nicht eine grössere Partie der Lunge gleichmässig infiltrirt ist, sondern nur einzelne, isolirte Stellen - es wäre demnach eine Jobulăre krebsige Pneumonie. Der entweder gleichzeitig mit der Lungeninfiltration oder später erfolgte Erguss in die Pleurahöhle bat nun die noch lufthaltigen Lungenpartien total comprimirt, so dass die Lunge, obgleich infiltrirt, docl im. Ganzen an Volumen bedeutend verloren bat.

Die Lunge ist $323 \mathrm{Grm}$. schwer und misst von der Basis bis zur Spitze 5 Zoll 8 Lin., während ihre Dicke 2 Zoll 2 Lin. beträgt.

In der récht grossen Leber befanden sich Krehsknoten von der Grösse einer Nuss bis zu der eines Hübnereies. Dic Knoten lagen theils an der Peripherie und bildeten die sclion im Leben gefüblten Hervorragungen, hatten dann übrigens die charakteristische nabelartige Einziehung, theils lagen sie mitten in der Lebersubstanz. Alle grenzten sich scharf gegen das normale Gewebe ab, hatten eine mehr oder weniger rundliche Form. Ibre Consistenz war ziemlich derb, der Durchschnitt matt glänzend, weiss mit rosenrothem Anflug. Auf Druck tritt ein milcliger Saft hervor. Die mikroskopische Untersuchung bestätigte, was schon der äussere Anblick zeigte, dass es nämlich Knoten von gewöhnlichem Medullarkrebs waren.

Der übrige Sectionsbefund bot nichts Bemerkenswerthes. 